\title{
Hybrid Natures - Ecosemiotic and Zoosemiotic Perspectives
}

\author{
Nelly Mäekivi ${ }^{1} \cdot$ Riin Magnus ${ }^{1}$
}

Published online: 8 April 2020

(C) Springer Nature B.V. 2020

\section{Introduction}

Hybridity has been explored in biology, technology, linguistics, cultural studies, etc., where the entities involved in the hybridisation process differ depending on the discipline. To discuss the aspects of how humans interact with other biological beings, what kind of a role human technologies may play in these connections, and what type of new relations are created, an international conference titled Semiotics of Hybrid Natures: Anthropogenic Ecosystems, Multimodalities, Transformed Umwelts took place in Estonia (Tartu) from 8th to 10th of November 2018. ${ }^{1}$ The objective of the conference was to gather scholars from fields of semiotics, technology, design, culture, philosophy, etc. to create new and exchange current knowledge on the myriad of phenomena of hybrid natures. This gathering also enabled the participants to clarify research methods applicable for analysing hybrid natures in the fields of ecosemiotics, zoosemiotics and environmental humanities. The current special issue is a follow-up to the conference, offering eco- and zoosemiotic perspectives on the phenomenon of hybrid natures and the novel meaning relations created in them.

\section{Hybrid Natures as a Concept and Phenomenon}

It is evident that human impact and involvement in the lives of other animals continues expanding, which, in turn, changes (for better or worse) the communication, sign

\footnotetext{
${ }^{1}$ The conference was supported by the Estonian Research Council (Grant PUT1363) and The Faculty of Humanities and Arts at the University of Tartu.
}

Nelly Mäekivi

nelly.maekivi@ut.ee

Riin Magnus

riin.magnus@ut.ee

1 Department of Semiotics, University of Tartu, Jakobi 2-302, 51014 Tartu, Estonia 
systems, ecologies and umwelts of species. Subsequently, human and nonhuman communities take on new forms - they create hybrid natures - , which are built on ecological relations where animal agencies are enacted. These natures are represented by human culture and social aspects, and manipulated by technological advancements. Understanding the dynamics and intricate semiotic aspects of hybrid natures that we share with other species is crucial for nature conservation endeavours, preventing and resolving environmental conflicts, and negotiating our relations with the rest of nature.

Hybridity has its roots in biology, where it denotes the offspring of any animals (or plants) that belong to different species. However, the concept of 'hybridity' has expanded its semantic scope and moved from biology to cultural realms of humans (see e.g. Stross 1999). Hybridism, after its metaphorical cultivation, presumes the existence of at least two initially separate and essentially different entities of which at least one can (but does not necessarily have to) be a (biological) agent. These entities, by intersecting with one another, acquire a novel joint-identity, not directly derivable from the characteristic of either party. The emergence of 'hybrid' marks the birth of new quality that is not reducible to its initial components, otherwise the new entity could be called assimilation, integration, mixture etc. In the framework of diaspora, hybridity indicates a sort of liminal space, where assimilation and integration emerge in the form of new ethnicities. In technology hybridity often refers to obscure delineations between the counterparts in human-computer interactions. Mikhail Bakhtin (1981) used the notion of 'hybridity' to denote the amalgam of two languages, which serve to undermine the dominating discourse. In the context of the history of ideas, hybridism might refer to the re-joining of once separated ideas and concepts as an indication of some paradigmatic shift. For biosemiotics, the issue of hybridity presupposes that at least one of the parties is a (biological) agent. On a larger scale, hybridity in biosemiotics means that approaching any research object must include social, cultural and natural aspects - they are ontologically part of the research object. With the ubiquitous presence of human sign systems and the impacts on the environment and other living beings that ensue from that, biosemiotics needs to attend to the novel meaning relations that are thereby induced. This implies that biosemiotics must continue and deepen the dialogue with social and cultural sciences. This would, of course, not be an entirely new endeavour (see e.g., Elliot 2019; Delahaye 2019; Mäekivi 2018).

What interests us here is hybridity as it pertains to various natures that we commonly share with other life forms. As the expanding attempts to revoke the nature-culture, natural-artificial, body-mind, humans-other species divides demonstrate, the restored union is at the same time a child of its own history, building its arguments as a debate with the past and never reaching the pre-division state of affairs, at least in Western environmental epistemology. By acknowledging the changed status of ideas as well as the changes in the environment, which certain ideas have contributed to initiating, one arrives at the concept of 'hybrid natures', which can be put side by side with 'novel ecosystems', 'new natures', 'anthropogenic landscapes', 'liminal spaces', 'multi-species environments', 'more-than-human social geographies', etc. They all refer to the previously non-existent combinations of living and non-living entities and elements on Earth, that human activity has contributed to bringing about. In addition to raising new ethical questions, environmental concerns, and providing new ways of living, hybrid natures also evoke questions about the nature of 'nature' and the human role in it. 
Human influence on different ecosystems is so vast, that we are seen as dominating the current geological epoch. Thus, also the notion of 'Anthropocene' has been introduced. Anthropocene has become a catchword, which these days encapsulates any negative impact that humans have on the natural world (e.g. anthropogenic climate change, anthropogenic biomes, biodiversity loss, etc.). Initially and often also these days, the term 'Anthropocene' refers to the chemical-biological changes on Earth that human activities have brought along (see Crutzen and Stoermer 2000). At the same time environmental humanities' scholars rather set their focus on the concomitant shifts in worldviews and images of man and the world alike. Despite the fact that the concept of 'Anthropocene' has been criticised for being an ideological construct, it has proved to be an irreplaceable tool in comprehending the changes taking place around us. Already in 1989, Bill McGibben wrote in his book The End of Nature that 'nature' as an independent category has become lost together with the ubiquitous presence of man: "An idea, a relationship, can go extinct, just like an animal or plant. The idea in this case is 'nature', the separate and wild province, the world apart from man to which he adapted, under whose rules he was born and died" (McGibben 2003: 48). This thought, in its various forms, is still being echoed in more contemporary writings. Bruno Latour, probably the most prominent advocate of hybridism these days, would refute the claim posed by McGibben with a reference to the origins of a distinct category of 'nature' in the (idea) historical developments in the West, while claiming that "the more we forbid ourselves to conceive of hybrids, the more possible their interbreeding becomes" (Latour 1993: 12). Hybridism of human and non-human phenomena gets its own taste and tone also in the works of Sarah Whatmore (2002), Donna Haraway (1991), Anna Tsing (2015) to name a few. The concept and stance has so far remained rather exempt of critical attention, with some exceptions. In Environments, Natures and Social Theory: Towards a Critical Hybridity (2015) the authors map the variety of authors and ideas, which follow the hybridism line in (recent) social theory, while calling for a critical hybrid worldview, which, besides detecting and advocating the entanglement of the social and the natural, should entail the reclaiming of the reconstructive potential of humans themselves. Recently, Andreas Malm's The Progress of this Storm: Nature and Society in a Warming World (2018) has criticised the hybridist lines of thought by reproaching, among other points, that in their post-Cartesian striving they in fact serve as a consequence of their own enemy (Malm 2018). Likewise, Alf Hornborg has argued for the necessity of keeping an analytical distinction between the factors deriving from the organisation of society and those principles proper to the prehuman universe (Hornborg 2016: 30). That would allow for an analysis of interactions while maintaining attentiveness to different principles of organisation.

Despite the fluctuating views on hybridity in the age of Anthropocene, the prevalence in using the concept indicates a need to apprehend and understand these complex systems that constitute the world we live in. How would hybrid phenomena appear through a semiotic lens and how are we to interpret them? What kind of theoretical tools does semiotics offer for analysing hybrid environments, sign systems and combinations of meanings? How can we mitigate human and nonhuman agencies in hybrid environments? These are some of the questions the articles of the current special issue address. 


\section{Overview of Articles Included in this Special Issue}

Before one can know anything about the specifics of hybrid natures as human-modified environments and their differences from natural ecosystems, one should have an idea of how the ecological relations are formed in the latter. Kalevi Kull's article "Semiotic Fitting and the Nativeness of Community" offers an insight into the semiotic mechanisms of ecological diversity. By relying on Daniel Janzen's similar notion of 'ecological fitting' Kull contrasts semiotic fitting with the commonly held view about coevolution and shared evolutionary history as the ultimate and only reason for the coexistence of certain species. The author claims that the semiotic fitting, with its local character, in turn contributes to the formation of native communities, which are defined through relations and not through origin.

Knowing how selection and learning function in the formation of natural communities, one can proceed to analysing how human activities and environments influence the choices the other species make or can make. In his article "Hybrid nature: Effects on Environmental Fundamentals and Species Semiosis" Almo Farina examines various consequences of human technological innovation on ecosystems and the semiotic ties that are essential for their functioning. By looking at the changes in terms of spatial patterns and resources, complexity, uncertainty, information and meaning, the author highlights mainly negative human impact on the functioning of ecological systems, even on occasions when the technological replacement of certain natural functions is available. Farina admits that the spread of hybrid natures as human-environment entanglements is these days unavoidable, yet whether the ways they have been shaped so far is inevitable is put to question. Cultural landscapes as landscapes with long-term co-formation of human and other species are contrasted with hybrid natures, which defy the long-term and regional development of ties between humans and other species, introducing abrupt cuts and disintegration instead. The establishment of rural sanctuaries as places where the human and non-human life could unfold in mutual attendance is proposed as a possible alternative to the current unplanned and destructive expansion of hybrid natures.

In hybrid natures, humans often do not have any direct contact with other species and the interactions are mediated by various human-created and human-centered artefacts. The design of such artefacts is often decisive in determining the type of relation humans and other species will have. Martin Avila's paper "(De)sign Responses as Response Diversity" addresses design as a tool for evoking and enhancing the diversity of ecological relations. The article offers examples of how the focus of design can be shifted in a way that would take into account the needs of other species and the ecological interactions that unfold in systems with human impact. It highlights two dimensions of design — the connective as well as the separating function, while showing, how this pertains not only to the human semiosphere, but how any artefact (of design) creates possibilities for interaction between certain agents, while excluding this for others. The opportunities for producing multispecies response diversity through design are discussed by introducing two experimental designs in agroecosystems, thereby demonstrating the application possibilities of (eco)semiotics.

One challenge that semiotics faces, is providing applicable empirical tools for scrutinising the myriad of interspecies interactions that take place in hybrid environments. In the article "Ecological Repertoire Analysis: A Method of Interaction-Based 
Semiotic Study for Multispecies Environments" Timo Maran offers a novel observation-based ecosemiotic method of ecological repertoire analysis. This entails accommodating nonhuman animals' competencies that help in explicating concealed meanings and values of the environment. By taking an interaction event as a basic unit of investigation, Maran incorporates umwelt theory, ecofield analysis and perceptual affordances to further elaborate the method that enables the researcher to analyse hybrid environments that humans share with other species. The synthesis of participatory observation and ecosemiotic means supports in coding semiotic patterns and processes that take place in a specific environment, and further aids in establishing motifs, and a general characteristic theme of the environment. This leads to a qualitative but evidence-based case study that Maran introduces as an application of and a test for the proposed method. By bringing out the advantages and potential shortcomings of the ecological repertoire analysis, he acknowledges the potential that the given method offers for studying hybrid environments.

Another approach that enables us to determine the multitude of interactions and effects that hybrid environments have on different species is offered by Jonathan Beever in his article "Sonic Liminality: Soundscapes, Semiotics, and Ecologies of Meaning". He turns his attention towards soundscapes, which give semioticians access to information transformation in liminal spaces. He argues that comprehending liminal spaces of human and nonhuman animals calls for technology-mediated biosemiotics analyses, which enable us to see how sign systems are interrelated when regarding soundscape ecology as fundamentally included in the science of semiotics. Beever stresses that using sound as a measure for ecological changes (e.g. influences of anthropogenic noise on the lives of other living beings) can direct us toward understanding sounds as meaning-carriers for every semiotic animal that interacts with its surroundings and other beings in a meaningful way. This insight serves to fulfill the soundscape ecology's function of biodiversity conservation. To exemplify his reasoning, Beever introduces a case study of a zoo, which is a sonic liminal space par excellence, and proves that soundscapes are indeed dynamic semiotic systems.

Developing new ways to study the interconnected aspects of truly hybrid environments, to connect the local and global, and to join views that at first glance do not seem to be totally compatible is undertaken in the article "Current Human Ecology in Amazonas and Beyond: A Multi-Scale Ecosemiotic Approach" written by Morten Tønnessen. He points out that the organismic and relational view of Uexküll's approach enables the researcher to move from local to global by changing the focus in the study of the human umwelt, and proposes to widen the scope of umwelt theory to be included in the ecosemiotic analyses of human ecology at different levels and scales. Tønnessen introduces the levels of physiological subject, experiential subject and environment and relates them to aspects of umwelt theory. Additionally, he proposes a distinction between different scales that concentrate on empirically verifiable interaction and relationality rather than on levels of study. This theoretical approach is exemplified in a case study of human and nonhuman animal relations in a settlement in the Central Amazon, where the matrixes for mapping human ecology is discussed.

Mirko Cerrone's article "Interspecies Relationships and Their Influence on Animal Handling: a Case Study in the Tallinn Zoological Gardens" provides insight into underdeveloped topic of keepers' influences on zoo animals. He bridges this gap by scrutinizing the ways that keepers perceive personal relationships with the animals they 
care for, and how this perception is translated into handling practices. As a case study Cerrone investigates the routines, attitudes and opinions that tie the keepers of a zoo to animals of different species and classes, and explicates the umwelt and perceived agency of these animals to uncover the biases that keepers have towards various species and individuals. He demonstrates that human-other animal umwelt overlap proves to be one of the main influential aspects that allows for interspecies communication. Consequently, species that possess human-like sociability and comparable body structures have a higher influence on handling practices and are more readily understood by the keepers. Cerrone further indicates that recognition of the subjective needs of animals that display behavioural similarities to humans not only allows changes in keeper routines, but also leads to alterations on an institutional level.

Continuing with zoos as specific hybrid environments, Matthew Chrulew's article "Reconstructing the Worlds of Wildlife: Uexküll, Hediger, and Beyond" traces the semiotic thought on the animal umwelt-centered design of zoos back to two classics of zoology and zoosemiotics - Jakob von Uexküll and Heini Hediger. In addition, Chrulew points out that it was not only the design of the zoo that Uexküll thought should follow the characteristics of the animal umwelt. The interactions with the keepers should also be planned in a way that would follow the biological premises of the animal. Likewise, Heini Hediger, as a director of various European zoos and as an intellectual inheritor of Uexküll, practiced and advocated a zoocentric approach to zoos. As Chrulew denotes, Hediger emphasised the 'change of meaning' when understanding animal behaviour and needs in a captive environment. Like Uexküll, Hediger laid much stress on the need to change the meaning that humans have for zoo animals for the sake of animals' well-being. In the end, both authors encouraged posing broader questions about the 'becoming' of animals in the modern world.

Acknowledgements We wish to thank all the authors and reviewers of this special issue for their hard work and productive cooperation. This editorial has received support from the Estonian Research Council (PUT1363 "Semiotics of multispecies environments: agencies, meaning making and communication conflicts") and PRG314 "Semiotic fitting as a mechanism of biocultural diversity: Instability and sustainability in novel environments" of the Estonian Ministry of Education and Research.

\section{References}

Bakhtin, M. (1981). The dialogic imagination: Four essays. Austin: University of Texas Press.

Crutzen, P. J., \& Stoermer, E. F. (2000). The 'Anthropocene'. Global Change Newsletter, 41, 17-18.

Delahaye, P. (2019). A semiotic methodology for animal studies. Cham: Springer.

Elliot, N. L. (2019). Observing wildlife in tropical forests. 1: A geosemeiotic approach. Bristol: Delome Publications.

Haraway, D. (1991). Simians, cyborgs, and women: The reinvention of nature. New York: Routledge.

Hornborg, A. (2016). Global magic: Technologies of appropriation from Ancient Rome to Wall Street. New York: Palgrave Macmillan.

Latour, B. (1993). We have never been modern. Cambridge: Harvard University Press.

Malm, A. (2018). The progress of this storm: Nature and society in a warming world. London: Verso.

McGibben, B. (2003). [1989]. The end of nature: Humanity, climate change and the natural world. London: Bloomsbury.

Mäekivi, N. (2018). The zoological garden as a hybrid environment - A (zoo)semiotic analysis. Tartu: Tartu University Press. 
Stross, B. (1999). The hybrid metaphor: From biology to culture. The Journal of American Folklore, 112(445), 254-267.

Tsing, A. (2015). The mushroom at the end of the world: on the possibility of life in capitalist ruins. Princeton: Oxford: Princeton University Press.

Whatmore, S. (2002). Hybrid geographies: natures, cultures, spaces. London: Sage.

White, D. F., Rudy, A. P., \& Gareau, B. J. (2015). Environments, natures and social theory: Towards a critical hybridity. London: Palgrave.

Publisher's Note Springer Nature remains neutral with regard to jurisdictional claims in published maps and institutional affiliations. 